\title{
Randomised clinical trials: a source of ethical dilemmas
}

Fernando Verdú-Pascual and Ana Castelló-Ponce University of Valencia, Spain

\begin{abstract}
Advances in medicine are closely linked to clinical research, but certain study procedures may be in conflict with the fundamental principles of ethics and codes of conduct in medicine. Following an analysis of two studies involving treatments for acute myocardial infarction (AMI), the admissibility of continuing a study was questioned after the initial results for two types of treatment showed that one was significantly better than the other. Also considered doubtful was the information provided to patients with the object of obtaining their informed consent.

(Fournal of Medical Ethics 2001;27:177-178)
\end{abstract}

Keywords: Clinical trial; randomisation; medical ethics

In a recent review of the current state of treatment for acute myocardial infarction (AMI), we could not help the words of Sniderman, in the conclusion of his viewpoint, coming into our minds: "we clinicians cannot become so weary that we abandon the responsibility of thinking for ourselves". "The results of each and every study present us with appropriate material for the exercise of sound judgment, which should be an essential prerequisite for the obtaining of meaningful results. This is of paramount importance in the field of medicine because medicine involves choices intended to increase wellbeing and save lives.

We recently found ourselves in an ethical predicament following a review of publications focusing on the advantages and disadvantages of performing systemic thrombolysis as opposed to primary angioplasty in cases of AMI. According to the results of current multicentre studies, ${ }^{2-6}$ a large number of patients have been involved in treatments in hospitals which are primarily equipped and staffed for providing either one or the other of these two alternatives on a systematic basis. These studies have not therefore offered conclusive results, although there is a certain tendency to consider primary angioplasty as the therapeutic measure of choice.

Our ethical dilemma arose following the review of another trial dealing with the same problem. ${ }^{7}$ The trial to which we refer was undertaken in a centre with a coronary intervention team which was available 24 hours a day. The primary objective of the study was to examine in-hospital deaths. There were secondary objectives, such as examining the occurrence of nonfatal reinfarction, post-infarction ischaemia and the need for revascularisation after the initial treatment.

With these objectives in mind, patients were selected using exclusively designed criteria and then randomised into one of the two therapeutic alternatives. Participation was on a voluntary basis after informed consent had been given. Two of the results obtained by the investigating team were:

1. The in-hospital mortality rate was $2.8 \%$ for the group undergoing primary angioplasty $(n=109)$ and $10.8 \%$ for the group receiving systemic thrombolysis $(\mathrm{n}=111)$.

2. The mortality rate after six months was $4.6 \%$ for the group undergoing primary angioplasty $(n=109)$ and $11.7 \%$ for the group receiving systemic thrombolysis $(n=111)$.

The rates show that the study provided sufficient indications that patient survival was significantly higher for patients receiving primary angioplasty. And it is at this point that certain doubts arise as to the ethical nature of this study. If 220 patients were treated over a period of just under five years (July 1991 to May 1996) and survival rates as indicated above were obtained, we can suppose that after studying half the sample, the results already pointed towards significant differences between the two treatments.

Given these circumstances, is it ethical to continue such a clinical trial? Is it ethically acceptable to expose the remaining patients to two types of therapy offering such significantly different results? We should bear in mind that the trial was being conducted at a hospital centre which was permanently equipped to undertake both of the interventions being tested. Theoretically, if primary angioplasty had been used to treat the remaining patients of the sample, the hospital would have saved the lives of six people during the hospitalisation period, and of six to seven people in the following six months. In all, this means 12 to 13 people could have been saved. 
The other two questions intimately linked to this problem concern the informed consent obtained from the patients. According to this study all patients were suitably informed and consented to participation in the clinical trial. We should first ask, however, whether the intensive coronary care unit where a patient is being treated for an imminent life-endangering situation is the appropriate place to solicit consent for a randomised clinical trial. But even more importantly, what kind of information was given once the trial was well under way? At the start of the trial only limited information as to risks and expectations could be given to the patient, based on prior knowledge of the problem. Yet, as the trial advanced, the results already obtained would show a tendency towards primary angioplasty as the better option, simply because survival is better. Was this information given to voluntary participants at that time? We doubt that it is morally right not to inform the patient that an option exists that may be considered to prevent almost $75 \%$ of deaths in the first few hours following an infarction and approximately $60 \%$ in a six-month period following that time.

Advances in medicine are certainly desirable and these are necessarily linked to clinical research; yet there are times when fundamental ethical and medical principles-the traditional Hippocratic oath or more recent interpretations such as the Oviedo agreement - are faced with an ethical dilemma. ${ }^{8}$ The case described here is surely one in which no clinician should abandon the responsibility of thinking and analysing the clinical trial situation, because we are primarily responsible for safeguarding the health and survival of people under our care.
Fernando Verdú-Pascual, MD, PhD, is Professor of Legal Medicine, the University of Valencia, Spain. Ana Castelló-Ponce, PhD, Sci, is a Biochemist in the Department of Legal Medicine, College of Medicine and Odontology, at the same university.

\section{References}

1 Sniderman AD. Clinical trials, consensus conferences, and clinical practice. Lancet 1999; 354:327-30.

2 Zahn R, Koch A, Rustige J, Schiele R, Wirtzfeld A, Neuhaus KL, et al. Primary angioplasty versus thrombolysis in the treatment of acute myocardial infarction. ALKK Study Group. American fournal of Cardiology 1997;79:264-9.

3 Every NR, Parsons LS, Hlatky M, Martin JS, Weaver WD. A comparison of thrombolytic therapy with primary coronary angioplasty for acute myocardial infarction. Myocardial infarction triage and intervention investigators. New England fournal of Medicine 1996;335:1253-60.

4 Holmes DR Jr, White HD, Pieper KS, Ellis SG, Califf RM, Topol EJ. Effect of age on outcome with primary angioplasty versus thrombolysis. Fournal of the American College of Cardiology 1999;33:412-19.

5 The global use of stategies to open occluded coronary arteries in acute coronary syndromes (GUSTO IIb) angioplasty substudy investigators. A clinical trial comparing primary coronary angioplasty with tissue plasminogen activator for acute myocardial infarction. New England fournal of Medicine 1997;336:1621-8.

6 Zahn R, Schuster S, Schiele R, Seidl K, Voigtlander T, Hauptmann KE, et al. Differences in patients with acute myocardial infarction treated with primary angioplasty or thrombolytic therapy. Maximal individual therapy in acute infarction (MITRA) study group. Clinical Cardiology 1999;22:191-9.

7 Garcia E, Elizaga J, Perez-Castellano N, Serrano JA, Soriano J, Abeytua $\mathrm{M}$, et al. Primary angioplasty versus systemic Abeytua $\mathrm{M}$, et al. Primary angioplas enterior myocardial infarction. Fournal of the American College of Cardiology 1999;33:605-11.

$8 \mathrm{http}: / /$ conventions.coe.int/treaty/en/Treaties/Html/164.htm

\section{News and notes}

\section{Life without Disease: Advanced European Bioethics Course}

This year's Advanced European Bioethics Course, Life without Disease, will be held from 15 - 17 November in Nijmegen, the Netherlands.

Subjects will include: stem cell research; xenotransplantation; tissue engineering; cloning; reproductive planning, and pharmacogenetics.
For more information contact: N Steinkamp, Catholic University Nijmegen, 232 Department of Ethics, Philosophy and History of Medicine, PO Box 9101, 6500 HB Nijmegen, the Netherlands. Tel: int. 31-243615320; fax: int. 31-24-3540254; email: n.steinkamp@efg.kun.nl 